\title{
Tackling the Shortage of Donor Kidneys: How to Use the Best that We Have
}

\author{
Norberto Perico ${ }^{a}$ Piero Ruggenenti ${ }^{a}$ Mario Scalamogna ${ }^{b}$ \\ Giuseppe Remuzzia \\ aDepartmentof Medicine and Transplantation, Ospedali Riuniti Bergamo, Mario Negri Institute for Pharmacological \\ Research, Bergamo, and ${ }^{b}$ Centro Trasfusionale e di Immunologia dei Trapianti Ospedale Maggiore Policlinico \\ Milano, Centro Interregionale di Riferimento per l'Area Operativa Nord Italia Transplant, NITp, Milan, Italy
}

\author{
Key Words \\ Marginal kidney donors · Dual kidney transplant · Organ \\ shortage · Donor criteria - Graft survival
}

\begin{abstract}
Shortage of kidney donor is still a major limitation for renal transplantation programs. This review focuses on the emerging practices, adopted to increase transplant activities, of expanding the criteria for donor and recipient selection without exposing the recipient to the drawbacks of a graft with inadequate nephron mass. Expanding the donor pool inevitably led to consideration for kidney transplantation of organs from older donors or from donors with hypertension, diabetes or other renal diseases. To fit the reduced performance of these suboptimal organs with the renal requirement of the recipient, selection of recipients with reduced metabolic requirements or increase of nephron mass by simultaneous transplantation of two suboptimal kidneys in the same recipient have been pursued. However, a critical aspect of both approaches is to quantify functioning nephron mass provided to the recipient by pre-transplant kidney biopsies. Morphological parameters assessed on kidney biopsies at the time of donor evaluation may serve to quantify the preserved tissue and to discriminate chronic
\end{abstract}

irreversible lesions from acute changes that may account for a transiently impaired renal function in the donor, but that may recover after transplant.

Copyright $@ 2003$ S. Karger AG, Basel

\section{Introduction}

During the last decades the progress in transplantation has been impressive. Thanks to the advances in surgery and medical treatments, and the development of new immunosuppressive drugs, more and more patients can be transplanted successfully. About 1 million people have received an organ, 73 kidneys from cadaver donors have survived more than 25 years, 17 heart and 27 liver transplant recipients more than 15 years $[1,2]$. As post-transplant care and survival rates continue to improve, the number of indications for which transplantation was the therapy of choice grew. While the transplant community attempts to keep up with the increasing demand for transplantable organs, the supply continues to fall far short of the need. This also applies to kidney transplant programs. Promotion of organ donation has resulted in a gradual but steady increase in donors, but unfortunately the disparity between the number of organs available for transplantation and the number of patients awaiting transplantation

\section{KARGER \\ Fax +41613061234 \\ E-Mail karger@karger.ch \\ www. karger.com \\ (c) 2003 S. Karger AG, Basel \\ 0250-8095/03/0234-0245\$19.50/0 \\ Accessible online at: \\ www. karger.com/ajn}

Norberto Perico, MD

Mario Negri Institute for Pharmacological Research

Via Gavazzeni 11

IT-24125 Bergamo (Italy)

Tel. +39035 319888, Fax +39035 319331, E-Mail perico@marionegri.it 
continues to increase. It has been estimated that the number of patients with end-stage renal disease - for most of whom renal transplantation is the treatment of choice - is increasing at the rate of $7-8 \%$ per year in the United States [3]. The United Network for Organ Sharing (UNOS) database shows that between 1988 and April 2002 , the number of patients on a waiting list for renal transplantation increased from 13,943 to 51,753 patients [4]. From 1988 to 2000 the patients' waiting time has almost tripled from a median of 400 days to more than 1,100 days [4], and the number of patients who have died every year awaiting a cadaveric renal transplantation has increased from 736 to 2,875, a 290\% increase [4]. Moreover, in 2000 only $26 \%$ of the patients on the waiting list for a kidney transplant actually underwent renal transplantation [4]. Also in most European countries waiting lists for kidney transplantation are in a similar or worse condition than a decade ago [1], making the severe shortage of cadaveric organ donors the major obstacle in preventing the full development of a transplant program and imposing a severe limit to the number of patients who benefit from this form of therapy worldwide. The challenge of expanding the donor pool has forced the community to look at new approaches to organ donation and to explore new sources of transplantable organs. As a result, over the past 10 years not only have organ donation rates changed, but so have the characteristics of the kidney donors themselves.

This review examines some of the changes reported in the past few years in the field of kidney transplantation, focusing on the different strategies adopted to increase transplant activities by expanding the criteria for donor and recipient selection without exposing the recipient to the drawbacks of inadequate nephron mass supply. Expanding the donor pool inevitably led to consideration for kidney transplantation of suboptimal organs (i.e. organs with reduced nephron number) from older donors or from donors with hypertension, diabetes, or any other renal diseases. To fit the reduced performance of these suboptimal organs with the renal requirements of the recipients, different strategies have been pursued, namely: (1) selection of recipients with reduced metabolic requirements (i.e. older or 'small' recipients); (2) increase of nephron mass supply by simultaneously transplanting two suboptimal kidneys in the same recipient. As we will discuss in this Review, a critical aspect of both approaches is to quantify functioning nephron mass provided to the recipient by pre-transplant kidney biopsy. Functional parameters are often unreliable because of a series of confounding factors that can affect donor renal function in an intensive care unit. Morphological parameters assessed on kidney biopsies at the time of donor evaluation may serve to quantify the preserved tissue and to discriminate chronic irreversible lesions from acute changes that may account for a transiently impaired renal function in the donor but that might recover after the transplant.

\section{The Expansion of Donor Criteria for Single Kidney Transplantation}

One strategy that has been used to address the perennial and increasingly critical shortage of kidneys for transplantation is the expansion of the cadaveric kidney donor pool to include those who might have been deemed unsuitable in earlier times $[5,6]$. At the beginning, it was necessary to demonstrate that transplantation technology could provide viable solutions for patients with failing organs. In order to assure the best possible outcomes, the pioneering transplant clinicians applied strict criteria when selecting potential donors and recipients [7, 8]. They mainly included age limits, ischemia time, and serious infection or malignancy [9]. Potential donors were excluded if they were diabetics, hypertensive or had organs with any degree of anatomical or functional abnormality, such as kidneys with multiple arteries or partial ureteropelvic junction obstructions [10-13]. Further, donors who died of cardiovascular diseases were eliminated in favor of trauma victims [14]. In addition, there were many organ-specific exclusion criteria that for kidney included elevated serum creatinine $(>1.3 \mathrm{mg} / \mathrm{dl})$ or abnormal glomerular filtration rate (GFR) $[12,13]$. Although the criteria above served the transplant community and their patients well, standards were established without an understanding of the impact modern therapies would have in bringing a wider range of patients, many of them sicker than those previously seen, to an expanding number of transplant centers $[15,16]$. Moreover, the transplant community began to note that certain donor variables did not significantly correlate with graft function after transplantation $[17,18]$, and that many potential donors were being eliminated on the basis of non-wellvalidated criteria [17]. Transplant centers have repeatedly re-evaluated and up dated their donor-selection criteria in an effort to expand the donor pool without compromising safety $[19,20]$. There are few universally applied donor criteria; standards for donor approval continue to vary from center to center. This reflects the fact that there is no universal definition of what constitutes an ideal kidney for transplantation. Earlier limits for adult kidney donor 
criteria included: age between 16 and 50 years, cold ischemia time $\leq 24 \mathrm{~h}$, no systemic bacterial, fungal, or viral infections, exclusion of diabetes, hypertension, or anatomical abnormalities and normal renal function as serum creatinine $<1.3 \mathrm{mg} / \mathrm{dl}$ (in adult donors) [9]. As a result of the numerous re-evaluations of donor standards, many criteria have recently become less tightened. Nevertheless, a few exclusion criteria have become absolute or more restrictive. This has allowed to test more expanded limits for donor criteria, such as age up to 75 years, cold ischemia time up to $40 \mathrm{~h}$, no infections only in donated organ, systemic bacteria or fungal infection if responsive to medications, no HIV, no hepatitis B or CreutzfeldJacob disease, diabetes excluded only in pancreatic transplant, hypertension/hypotension excluded only if organ damaged, minor functional or anatomical abnormalities acceptable, and serum creatinine $\leq 3.0 \mathrm{mg} / \mathrm{dl}$. At the same time the concept of 'suboptimal' or 'marginal' kidney has been developed, although a broadly accepted definition of the term marginal grafts is currently missing. This is based on the presence of certain pre-transplant correlates of potential diminished graft survival that lead to characterize marginal grafts by donor age, serum creatinine or creatinine clearance, anatomical variation and the degree of sclerosis at biopsy $[21,22]$. We would suggest arbitrarily that renal grafts be classified as 'marginal' when one or more of the following conditions is present: donor age $>65$ years, serum creatinine $>1.5 \mathrm{mg} / \mathrm{dl}$ during a stable phase of the donor, creatinine clearance $<90 \mathrm{ml} /$ min (by Cockcroft-Gault), the presence of diabetes or hypertension, $>1$ renal artery, degree of glomerulosclerosis $>15 \%$, in addition to the cause of death (nonheartbeating cadaver donors) and duration of cold ischemia (>36 h).

\section{The Older Donor}

There are well-known age-associated changes in most vital organs, including glomerulosclerosis, tubular atrophy and interstitial fibrosis in the case of kidneys [23]. This may give reason to the observation that graft survival of older kidneys is lower than that of kidneys from younger adult donors $[24,25]$. The poorer graft survival of old kidneys has been attributed to a greater susceptibility to ischemia-reperfusion injury and delayed graft function, which in turn may make the allograft more susceptible to acute rejection and graft failure [26-28]. The reduced number of functioning nephrons in older donor kidneys also feature them as more susceptible to chronic hyperfiltration injury, eventually contributing to chronic allograft nephropathy [29]. Therefore, during the past decade, while the number of elderly donors has increased, the rate of discard of such donors has also increased, because many centers are still reluctant to use organs under the pressure of the recent managed care system and the fear that they will have a negative effect on their own centerspecific data. On the other hand, many centers have been utilizing most of these donors because of acute organ shortage and with very acceptable results [23, 30-32]. In cadaveric renal transplantation Sautner et al. [33] have reported similar graft survival at 1 and 3 years for kidneys taken from donors older than 60 years, compared with kidneys from younger donors. Others have also reported similar 1- and 2-year graft survival in 30 kidneys taken from donors aged 56-73 years compared with 64 kidneys from younger donors [31]. However, the serum creatinine in the recipients of older donors was significantly higher than in recipients of younger ones. Spanish results of 250 kidneys from donors aged 55-72 years compared with younger donors also documented no difference in graft survival at 2 and 5 years, but the serum creatinine was significantly higher in the older kidneys [34]. More recent analyses performed by the Establissement Français des Greffes - the French Registry of Organ Transplantation in 7,209 cadaver kidney transplant recipients from 1996 to 2000 of which $7.6 \%$ were from donors aged over 60 [21] found that donor age was not an independent predictor of 3 year allograft survival. Studies with $>5$ years of follow-up, however, found a major impact of donor age on graft outcome [35].

A still open question is whether old kidneys should be given to old recipients. The analysis of the UNOS data base on 45,922 cadaver donor transplants carried out between 1987 and 1994 reported that renal function (as serum creatinine concentration) 1 year post-transplant was better in older ( $>60$ years) than younger ( $<60$ years) recipients of kidneys from donors over age 60 [36]. More recently, the Eurotransplant Senior Program 'old for old' [37] confirmed the efficacy of using old kidneys $(>65$ years) for recipients older than 65 years. After a mean follow-up of 28 weeks there was no difference of serum creatinine level in the 'old for old' group and in the control recipients (mean donor age: 48 years; mean recipient age: 47 years) transplanted according to the ordinary Eurotransplant criteria. From these findings it has been suggested that older kidneys may be better suitable for older recipients given the lower function demand due to age. On this belief, transplantation centers are more likely to accept older donor kidneys for older recipients (and younger kidneys for younger recipients) than would be expected [38], and this procedure is now becoming a com- 
mon practice. By preferentially transplanting older donor kidneys (which are less likely to survive as long as younger donor kidneys) into older recipients (which are more likely to die with a functioning allograft) overall graft survival might be optimized and even improved [39]. The effects of specific donor and recipient age combinations in multivariate analysis has been evaluated using data from the United States Renal Data System (USRDS) of 74,297 first cadaver kidney transplantation in 1988 to 1998 [38]. According to this analysis both recipient and donor age affected graft survival but the effects of donor age are much stronger than those of recipient age. However, giving older kidneys to older recipients had little independent effects on graft survival when the intrinsic effects of recipient and donor age per se were also taken into account. Indeed, there did not appear to be any consistent interactions of specific recipient-donor age combinations. In other words, across all of the possible recipient-donor age combinations there were no specific interactions that would suggest that giving older or younger kidneys to older or younger recipients altered the risk of graft failure. Although overall these data do not support the common practice of giving selectively older kidneys to older recipients, the risk of transplanting suboptimal older kidneys into ideal young recipients should not be underestimated, and final decision should only be taken according to biopsy findings.

Evidence is available of worse graft outcome in older kidneys when they are subjected to longer cold ischemia time, and when renal biopsy shows $>20 \%$ glomerulosclerosis or more than grade 1 arteriosclerosis or interstitial fibrosis as changes related to aging process [23, 30, 31].

The latter finding points out that a kidney biopsy at the time of organ harvesting should help define the degree of structural changes present, and thereby permit an individual judgment on the suitability of an organ donor. The presence of glomerulosclerosis, interstitial fibrosis, tubular atrophy, arteriosclerosis and arteriolar hyaline changes in any given donor biopsy frequently parallels one another and increases with donor age, reflecting the well-known aging process in the kidney [40]. However, with increasing age the frequency of atherosclerosis, hypertension and diabetes also increase, which may accelerate renal changes [41]. Therefore, donor age alone cannot be the deciding factor for accepting a donor. In addition, ageassociated morphological changes show considerable individual variability in the general population. According to an autopsy study, the percentage of sclerotic glomeruli caused by aging can largely vary from $0.2-16.7 \%$ at age 55 years, and $1.5-23 \%$ at age 75 years [40]. Conversely, mild histologic abnormalities have been reported in younger individuals much more commonly than it is generally believed [42]. Likewise the degree of parenchymal injury in elderly donors with a history of hypertension and diabetes will be a function of the duration and severity of disease. This further underlines the limit of choosing to reject kidney donors on the basis of age alone, and the usefulness of biopsy evaluation of older donors to have important information about their suitability for transplantation.

Reports of the value of histologic examination of donor kidney in clinical transplantation are, however, limited and have yielded variable results, mainly due to lack of clear definition of the histologic parameters studied. A prospective study of a consecutive series of 200 donors failed to find the proportion of glomerulosclerosis in single procurement wedge biopsies as a major donor factor influencing graft survival [43]. Indeed, glomerulosclerosis as high as $25 \%$ or more had an acceptable 3 year graft survival rate of $74.7 \%$, a value comparable to that of recipients of kidneys with percentage of glomerulosclerosis $\geq 20 \%(78.4 \%)$ and $0-19 \%(82.2 \%)$. This view is challenged by a retrospective study of kidney biopsies from 78 marginal donors ( $>50$ years old, cold ischemia time $>30 \mathrm{~h}$ ), in which renal allograft function after transplantation was inversely related to the severity of histologic changes in the donor biopsy [42]. At 1 year post transplant all recipients of kidneys with $\geq 20 \%$ glomerulosclerosis had severe graft dysfunction (creatinine clearance $<34 \mathrm{ml} / \mathrm{min}$ ), but only in 25,46 , and $60 \%$ transplant recipients of donor kidney with $0 \%, 1-10 \%$, and $11-20 \%$ glomerulosclerosis, respectively. This is in line with data that post-perfusion biopsies with $>20 \%$ glomerulosclerosis was associated with a $38 \%$ graft loss and a mean serum creatinine level of $2.6 \mathrm{mg} / \mathrm{dl}$ at 6 months post-transplant [44]. However, this conclusion was derived from a study group of only 8 patients with an unusually high percent of glomerulosclerosis (median 40\%). Other investigators showed a similar correlation between a histologic chronicity score obtained at post-perfusion biopsy and creatinine clearance measured 3 months later [45]. Successful use of donor with an average of $10 \%$ glomerulosclerosis has also been reported, but the range of percentage glomerular injury was not provided [46]. The discrepancy in the results reported so far may be due to differences in the number of glomeruli in the biopsy sample to achieve a significant prediction of graft survival and the number of transplant recipients examined. The finding that the percentage of glomerulosclerosis varies depending on the cortical depth (subcapsular, inner or outer cortex) of the 
biopsy or histologic examination [40] provides an additional explanation and suggests that comparisons of results should be limited to studies using the same sampling technique. The predictive value of pretransplant assessment of percentage glomerular sclerosis by donor biopsy is further supported by a very recent study on 210 kidney allografts followed up to 4 years post-surgery [22]. Patients with $>20 \%$ glomerular sclerosis had the poorest renal function at 1 year and the steepest rate of decline in GFR. Of interest, although there was an overall correlation between donor age and percentage glomerulosclerosis, over $40 \%$ of older donors ( $<55$ years old) had no glomerulosclerosis whatsoever. These data underscore the variability in the rate of renal aging in the general population and the important information a pretransplant biopsy can provide. Thus, age is not a good discriminating factor between good and 'marginal' kidneys. At variance, a biopsy taken at procurement may provide information for the most appropriate allocation of the graft.

On the basis of the available data, it can be reasonably safe to recommend that kidneys from older donors can be successfully used if renal biopsy shows $<20 \%$ glomerulosclerosis; the kidneys should preferentially but not exclusively be given to older patients. Evidence, however, that recipients of single kidneys from old donors had significantly higher serum creatinine levels as compared with recipients of ideal grafts, arises some concern that nonideal kidneys might be at increased risk of premature failure in the long term.

\section{The Diabetic Donor}

In 1983, Abouna et al. [47] showed for the first time successful transplantation of kidneys from a donor with a 17-year history of insulin-dependent diabetes, diabetic nephropathy at histologic examination, and good renal function. Fourteen months after transplantation graft function in the two recipients was well preserved, as shown by creatinine clearance of 51 and $60 \mathrm{ml} / \mathrm{min}$, respectively. Interestingly, renal biopsy specimens taken 7 months after transplantation showed almost complete resolution of the nephropathy. Since then other centers have began to use diabetic donors for kidney transplantation with similar good results [48]. Two cases of diabetic cadaver donor kidney transplantation were reported by Orlowski et al. [49] at the Presbyterian/St Luke's Medical Center. In the first, graft functioned for 67 months before the patient died, with a working kidney, of myocardial infarction. In the second case the graft from a 12-year-old diabetic donor enlarged to normal adult size and functioned for 44 months before being lost due to chronic rejection. In both instances no diabetic changes on biopsy performed at several points post-transplantation were found. A very satisfactory graft function at 4 years posttransplantation has been also reported in a recipient of a kidney graft affected by diffuse diabetic glomerulosclerosis, but with normal renal function [50]. A similar case of a diabetic patient becoming a kidney donor, who also had impaired renal function, resulted in a good graft function at 3 months and no episodes of rejection when transplanted in a 40-year-old type I diabetic woman [51]. Moreover, recent analyses from the UNOS data registry confirmed that donor diabetes mellitus lasting more than 10 years was not a significant risk factor for graft and patient survival [52].

This suggests that diabetes itself should not be a barrier to organ donation, providing that organ function is normal or near normal. However, since the degree of parenchymal injury in donors with a history of diabetes mellitus is a function of the duration and severity of disease, biopsy findings in diabetic donors could potentially be a tool to exclude high-risk renal grafts from being transplanted.

\section{The Hypertensive Donor}

Donors with hypertension constitute suboptimal grafts and are rejected by many centers. To date, relatively small numbers of transplants have utilized kidneys from hypertensive donors [10] (table 1). Reports indicate that such transplants have achieved success when no initial evidence of compromised renal function existed. A study of 182 recipients of cadaveric kidneys from donors without a history of hypertension and 14 recipients of kidneys from mild hypertensive donors showed identical 5-year graft survival in the 2 groups [11]. A similar study [10] involving 440 ideal kidneys and 25 hypertensive kidneys noted a trend toward an increased rate of 5 year graft survival with the ideal kidneys ( 59 vs. $47 \%$ ). When re-transplanted patients were removed from the analysis, however, this difference was eliminated. Overall, the precise correlation of arterial hypertension and chronic graft deterioration remains unclear although already existing long-term hypertension of the recipient is considered a risk factor [53]. Analysis of cadaveric renal allografts from donors $\geq 55$ years old with a history of long-term arterial hypertension reported to UNOS demonstrated decreased long-term function with reduced creatinine clearance [52, 54]. Similar results have been reported from the CTS database [55]. Recent investigations in Australia [56], United States [54], and France [21] have demonstrated that donor hypertension is a significant independent risk factor for 
Table 1. Outcomes of single marginal kidneys from donors with or without history of hypertension

\begin{tabular}{|c|c|c|c|c|c|c|c|}
\hline \multirow[t]{2}{*}{ Hypertension } & \multicolumn{2}{|c|}{$\begin{array}{l}\text { Troppmann et al. } \\
\text { [Transplant Proc, 1991] }\end{array}$} & \multicolumn{2}{|c|}{$\begin{array}{l}\text { Madden et al. } \\
\text { [Transplant Proc, 1993] }\end{array}$} & $\begin{array}{l}\text { Carter et al. } \\
\text { [Transplantation, 2000] }\end{array}$ & \multicolumn{2}{|l|}{$\begin{array}{l}\text { Weighted } \\
\text { average }\end{array}$} \\
\hline & $\begin{array}{l}\text { yes } \\
(n=14)\end{array}$ & $\begin{array}{l}\text { no } \\
(\mathrm{n}=182)\end{array}$ & $\begin{array}{l}\text { yes } \\
(\mathrm{n}=25)\end{array}$ & $\begin{array}{l}\text { no } \\
(\mathrm{n}=440)\end{array}$ & $\begin{array}{l}\text { yes } \quad \begin{array}{l}\text { no } \\
(\mathrm{n}=557) \quad(\mathrm{n}=2,679) \\
>10 \text { years* }\end{array}\end{array}$ & $\begin{array}{l}\text { yes } \\
(\mathrm{n}=596)\end{array}$ & $\begin{array}{l}\text { no } \\
(\mathrm{n}=3,301)\end{array}$ \\
\hline Graft survival: n (\%) & $\begin{array}{l}9(64) \\
\quad \text { (at } 5 y\end{array}$ & $\begin{array}{l}116(64) \\
\text { ars post-Tx) }\end{array}$ & $\begin{array}{l}12(47) \\
\quad \text { (at } 5 y\end{array}$ & $\begin{array}{l}260(59) \\
\text { ars post-Tx) }\end{array}$ & $\begin{array}{r}317(57) \quad 1,741(65) \\
(\text { at } 3 \text { years post-Tx) }\end{array}$ & $338(56.7)$ & $2,117(64.1)$ \\
\hline
\end{tabular}

post-Tx $=$ Post-transplant.

* Hypertension history $>10$ years.

graft survival, in particular when the history of hypertension exceeds 10 years [54]. Since arterionephrosclerosis is usually the cause of worse outcomes of grafts from hypertensive donors, a kidney biopsy remains the best approach to assess the quality of the graft before the transplant is performed.

\section{The Donor Renal Function}

The importance of donor renal function as a risk factor for subsequent graft survival is still debated. From a recent multivariate analysis of donor risk factors for graft survival in kidney transplantation, pre-harvesting serum creatinine concentration higher than $1.7 \mathrm{mg} / \mathrm{dl}$ has been shown as a significant independent factor [21]. Similarly, donor serum creatinine also time-dependently influenced graft outcome, as derived from analysis of 1,124 transplant patients from the Rotterdam Transplant Center [57]. The excess of graft loss was already evident in the immediate postoperative phase, increased thereafter, and was strongly correlated with the degree of serum creatinine increase. However, pre-transplant serum creatinine levels are not reliable indicators of renal functional reserve of the donor, since they may reflect acute, functional changes occurring before and during the observation of the donors, rather than structural, irreversible changes of the kidney. On the other hand, serum creatinine levels within the conventional normal ranges do not exclude severe structural lesions and decreased functional reserve, in particular in elderly subjects [58]. Thus, serum creatinine is a poor screening test for renal failure in elderly subjects [58]. Again, these findings suggest that renal biopsy is still the gold standard to assess transplant eligibility of kidneys from marginal donors.

\section{Grafts with Prolonged Ischemia Time}

Until recently, many centers were reluctant to utilize kidney grafts preserved for longer than $30 \mathrm{~h}$, whether by cold storage or hypothermic perfusion. This policy was based on the fact that there are adverse consequences following prolonged ischemia, which include increased incidence of primary nonfunction, increased rate of delayed graft function requiring hemodialysis and reduced graft survival, particularly when marginal donors were used. A comparison of graft survival for 57 kidneys preserved for as long as $30 \mathrm{~h}$ (mean 24) to that of 53 preserved $31-63 \mathrm{~h}$ (mean 38) showed a higher rate of delayed function, a longer period of initial hospitalization and a lower 2-years graft survival rate with longer cold ischemia time [59]. In the UNOS data analysis, odds ratios for 2-year renal graft survival were significantly different when ischemia time of $30-40 \mathrm{~h}$ or $>40 \mathrm{~h}$ were compared with $10-20 \mathrm{~h}$; however, the difference was small [60]. It has been shown that for every $12 \mathrm{~h}$ of cold ischemia time, there is a reduction in 5-year graft survival of approximately $2 \%$ [61]. Marginal grafts may be particularly sensitive toward prolonged ischemia. In an analysis of the UNOS database [60], 2year graft survival was significantly affected both by cold ischemia time and donor age, but these factors did not appear to interact. Cold ischemia time had a similar but small adverse effect on organ survival at every donor age. Thus, to improve the condition of marginal grafts (elderly, hypertensives) ischemic periods should be kept as brief as possible, regardless of the method of preservation.

\section{The Non-Heart-Beating Donors}

The current shortage of organs has led to the reintroduction of the old concept of non-heart-beating donation. In the early days of transplantation grafts were regularly recruited from non-heart-beating donors. There are now 
considerable data to show that the results of kidney, liver, and pancreas transplantation from controlled non-heartbeating donors are good, providing that the warm ischemia time is less than $30-45 \mathrm{~min}$, which is followed by in situ perfusion cooling of the organs [62]. High graft survival rates have been described for all organ systems although the incidence of initial poor and delayed graft function is elevated. Despite the poorer graft function of non-heart-beating donor kidneys in the early post-transplant period, the majority of data [63] show comparable allograft survival between non-heart- and heart-beating donor kidneys at 3 years [64], 5 years [64, 65] and 10 years [66] after transplantation. These findings are also confirmed by retrospective analysis of 24 years experience [67]. However, the impact of warm ischemia time on graft survival is controversial $[65,68-70]$. Actually, the prolonged warm ischemia that may affect kidneys from nonheart-beating donors may increase the risk of delayed graft function, but does not seem to affect the graft performance in the long-term. Although grafts from non-heartbeating donors may offer the opportunity to increase organ supply, broad promotion of this approach should be discussed with care. Ethical issues related to the diagnosis of death, start of perfusion, and ultimately the impact of an increased incidence of delayed function on long-term graft outcome represent unsolved problems and require a cautious approach for the utilization of grafts from nonheart-beating donors in order not to jeopardize results of well-functioning donor programs [71].

\section{Multiple Renal Arteries and Vascular Anomalies}

Until recently, many centers have been reluctant to use kidneys with multiple arteries, especially when other suboptimal conditions exist, such as donor age and long cold ischemia time, for fear of technical complication and graft loss. Theoretically, multiple renal arteries are more likely to lead to technical complications during anastomosis with increased incidence of arterial stenosis and thrombosis $[72,73]$. Increasing the operating time and prolonging the relative cold ischemia time also induce ischemic damage to the ureter and eventually decrease graft survival $[72,73]$. Because approximately $30 \%$ of kidneys have multiple renal arteries, and in $10 \%$ of these the anomaly is bilateral, many good grafts are lost if such kidneys are discarded [74]. Recent experience by several centers has shown that the aforementioned theoretical problems can be avoided with good surgical techniques, and excellent graft survival can be obtained.

\section{Survival Benefit in Single Marginal Kidney Graft Recipients over Maintenance Dialysis}

In most series, allograft outcomes with single marginal kidneys are inferior to that of organs considered to be ideal [75-77]. Notwithstanding the diminished graft survival of marginal kidneys, renal transplantation improves quality of life [78, 79] and economic analysis suggests that transplantation is more cost-effective than dialysis [80]. Improved patient survival is a well-established benefit of renal transplantation but the magnitude of increased longevity is not uniform across patient subgroups [81-83]. Of interest, the estimated additional life-years gained from renal transplantation vary from 8 years in a diabetic recipient who is 60 years or older to 31 years in a nondiabetic recipient who is $20-44$ years old $[82,84]$. Thus, any survival advantage to be gained from receiving a marginal donor kidney is also likely to vary between subgroups of recipients. It has been shown that allograft loss terminates the patient survival benefit derived from kidney transplantation such that patients who lose graft function are at increased mortality risk unless repeat transplantation is performed [85]. Because marginal organs have comparatively diminished allograft survival, one may argue whether it is beneficial for a patient who is on the cadaveric renal transplant waiting list to accept an offer for transplantation with a marginal donor kidney. This answer is provided by a very recent historical prospective cohort analysis of US data derived from United Network for Organ Sharing (UNOS) and US Renal Data System (USRDS) registries, in which the survival of recipients of marginal kidneys $(n=7,454)$ was compared with that of wait-listed dialysis patients $(\mathrm{n}=113,187)$ and recipients of ideal cadaveric donor kidneys $(n=34,438)$ [52]. Donor kidney was defined marginal if one or more of the following criteria were fulfilled: donor age $>55$ years, donor history of hypertension longer than 10 years, donor history of diabetes mellitus longer than 10 years duration, nonheart-beating donors, and cold preservation time $>36 \mathrm{~h}$. Marginal kidney transplantation was associated with substantial reduction in mortality and improvement in life expectancy when compared with transplant candidates who remained on maintenance dialysis treatment. On the average, recipients of marginal kidney transplants lived 5 years longer than dialysis patients on waiting list for a transplant, whereas ideal cadaveric transplant recipients had a 13-year survival benefit. As in the case with the latter, the survival benefit of marginal donor kidney transplantation varied by cause of ESRD, recipient age, and race from 3 to 10 years. Despite the subgroup differences

Transplantation of Marginal Kidneys 
in the patient outcomes with marginal kidney transplantation, it is important to underline the perspective that successful kidney transplantation with marginal or ideal organs is associated with dramatic and substantial improvement in quality of life [78, 79]. Moreover, receipt of a marginal kidney transplant was not detrimental to patient survival in any subgroups.

\section{From Single to Dual Marginal Kidney Transplantation}

Manipulations of the renal mass have been recently receiving increased attention to improve the quality of grafts from suboptimal donors. The rationale rests on the observation that transplantation of a single marginal kidney provides a suboptimal number of nephrons to start, which serves to create the clinical counterpart of experimental reduction of renal mass [86]. In most cases, injuries from cold ischemia time, one or more acute rejections, and toxicity of medications, further reduce the already limited number of nephrons that a single suboptimal kidney provides [86]. This remnant kidney - now containing $20-30 \%$ of viable parenchyma or less compared to that in two optimal kidneys - initiates a selfperpetuating program of progressive deterioration as commonly seen in animals undergoing renal mass ablation [87]. That nephron mass is a determinant of chronic allograft failure has been formally tested in animal experiments showing that increasing the number of viable nephron mass by simultaneous transplantation of two kidneys into the same recipient effectively prevented the progressive deterioration in renal function that occurs in controls given a single kidney $[88,89]$. Thus, the use of two marginal kidneys - from donors more than 60 years old, or affected by diabetes, hypertension, or with evidence of non-nephrotic proteinuria - in a single recipient might be an option to improve the quality of single suboptimal donor grafts. The hypothesis is that if two marginal organs were given to the same recipient, this may result in more functioning nephrons than in single suboptimal or as many as in a single ideal kidney. One should consider the possibility of using those kidneys with less than $20 \%$ of renal mass injured [22]. This can be fulfilled with reasonable precision by performing renal biopsy of both kidneys immediately after their removal from the donor. In this case, the limit of using suboptimal kidneys would be balanced by the advantage for the patient of receiving a nephron mass anyhow larger even than that provided by a single ideal kidney. The overall higher number of func- tioning nephrons supplied by dual marginal kidneys should theoretically slow or even prevent the sequence of events associated with progressive deterioration of graft function, ultimately leading to graft loss.

In order to identify the available information on double kidney transplantation programs, an electronic search of MEDLINE, via PubMed of the literature published from 1996 through April 2003 was carried out. Additionally, reference lists of the relevant retrieved papers were checked. 102 potentially relevant articles were identified. The first presentation of dual grafting with adult kidneys in the United States was in 1996 as a preliminary report of the combined experience of the Universities of Maryland and Stanford [90, 91]. In 9 dual graft recipients of marginal donor kidneys (age $>60$ years, and/or history of longstanding hypertension or diabetes), with a mean follow-up of 6.6 months, renal grafts provided a mean serum creatinine of $1.6 \pm 0.3 \mathrm{ml} / \mathrm{dl}$ and a creatinine clearance of $43 \pm$ $3 \mathrm{ml} / \mathrm{min} / 1.73 \mathrm{~m}^{2}$. Suboptimal donor kidneys transplanted as double allografts had similar actuarial 1-year graft survival when compared with grafts from randomly selected recipients of single ideal donor kidneys $(<50$ years) (100 vs. 95\%). Since this report $[90,91]$, there has been a gradual acceptance and implementation of dual grafting procedure. In 1997, other investigators reported in a retrospective study the outcomes in 15 dual marginal graft recipients compared to 74 conventional single cadaveric graft recipients [92]. All transplants were carried out over the same time period under the same immunosuppressive protocol. The mean graft function at 18 months was similar in the two groups. The 1-year actuarial graft survival in the dual marginal kidney recipients versus the ideal donors was 87 and $91 \%$, respectively. In the same year, the analysis of the preliminary experience with double kidney transplants from adult cadaveric donor collected by the UNOS registry has been presented [93]. Sixty double kidney transplants were performed, including 25 in the younger donor group (age 18-49 years), and 35 in the older group (age $\geq 50$ years). Recipients of dual older donor kidneys had similar serum creatinine level at discharge and at 12 months post-transplant as compared to patients ( $\mathrm{n}=9,294)$ given a single ideal kidney graft. These patients also had comparable 1-year graft survival (90.8 vs. 87.5\%). More recently, evidence of excellent outcome in 50 recipients of dual kidneys from older donors ( $\geq 60$ years) has been provided as a report of the transplant program performed at Stanford University [94]. Fewer rejections, similar 3 month and 1-year serum creatinine levels were found in recipients of dual transplants versus recipients of single ideal kidney grafts. 
Reports of successful dual renal transplants from elderly kidney donors [95-97] or non-heart-beating donors [98] are also available in Europe. All these findings are corroborated by a recent prospective, case-control study involving transplantation centers in Europe, Canada and United States, aimed to compare the outcome of transplantation of two marginal versus single ideal kidneys [99]. Overall double and single kidney transplants were associated with remarkably good 6-month patient and graft survival, which reached $100 \%$ with both the procedures. Furthermore, the overall incidence of surgical or infectious complications was comparable. This is in line with preliminary evidence from uncontrolled [100-102] or small $[103,104]$ series showing a relatively good safety profile of the procedure, and would indicate that fear of more surgical complications or more infections should not prevent the systematic use of marginal kidneys in double procedure protocols. Moreover, in the multicenter trial [99] the incidence and duration of post-transplant anuria requiring continued renal replacement therapy, the rate of renal function, and the incidence of acute rejection were comparable in recipients of dual marginal and single ideal kidneys. Interestingly, double compared to single kidney patients had lower serum creatinine values over the last 5-month follow-up and lower diastolic blood pressure levels averaged during the entire study period. The finding that cases showed a trend to a better recovery would suggest that the increased number of nephrons provided by the double procedure might have contributed to enhance filtration power of the graft despite the older age of the donors.

An open issue remains long-term survival of transplants done by the simultaneous dual marginal kidney procedure. The remarkably low incidence of acute rejections and delayed graft function observed in most published series $[92,99,103,105,106]$ would indeed predict excellent long-term outcome. This is supported by very recent data from a large series of dual kidney transplantation (258 patients) enrolled from 11 USA and Canadian centers, and collected by the Dual Kidney Registry [107]. The donors were, on average, 59 years old and $50 \%$ of them had a history of hypertension. The 1- and 3-year graft survival rates (87 and $73 \%$, respectively) in dual transplant recipients are close to those (89 and $76 \%$ ) now reported in single transplant recipients from ideal donors recorded in the Scientific Registry of Transplant Recipient database [108], and are remarkably superior to those (80 and 60\%) reported in recipients of single kidneys from donors aged 65 or over [108]. Of note, reducing cold storage time may be the single most important aspect to ensuring long-term graft survival in recipients of aged dual kidney transplants [107]. These encouraging results are confirmed by a more recent small study showing that 10 dual kidney recipients had 4-year graft function and survival comparable to those of 10 age-matched controls receiving single cadaver kidney from ideal donors [109]. The UNOS registry database has also been used to compare the outcomes of 403 dual adult kidney transplantations and 11,033 single kidney transplantations from 1997 to 2000 [110]. Although, all together, dual kidneys resulted in inferior outcomes compared with single kidneys, when comparative analyses were restricted to kidney transplants from donors over 55 years of age, dual transplants from marginal donors and single transplant from ideal donors resulted in similar 3-year graft outcomes.

\section{Dual or Single Marginal Kidneys for Transplantation: Guide from Preimplantation Renal Biopsy}

The dual kidney transplantation program was developed mainly as a method to extend the use of aged donor kidneys from expanded criteria donors that would have otherwise been discarded. The parallel increasing use of single kidneys from elderly donors in transplantation programs worldwide raised, however, discussion on whether dual is actually better than single marginal organs as for the outcome of the grafts [111]. Theoretically, the larger functional mass provided by transplanting in the same recipient two suboptimal kidneys would offer a higher filtration power than would be achieved with a single marginal organ. This possibility is consistently supported by recent studies that formally compared double versus single renal transplant from marginal donors [94, 103, 105, 112-114] (table 2). Compared to single marginal kidney graft recipients, 15 dual graft recipients had significantly less delayed graft function, and graft function was better at 1, 4 and 12 weeks after transplantation [92]. The 1-year graft survival rates were not statistically different between the groups: $81 \%$ for single marginal and $87 \%$ for dual transplant. Jerius et al. [112] reported results of 28 patients who received double renal transplant and 21 given a single transplant from marginal donors. Donors were older than 55 years, or had diabetes mellitus, hypertension, greater than $15 \%$ glomerulosclerosis on biopsy, increasing creatinine or intrinsic renal parenchymal disease. The use of two kidneys instead of one from marginal donors resulted in a significant graft survival advantage at 1 and 2 years (96 vs. 77\%, and 96 vs. 73\%, respectively). 
Table 2. Outcomes of dual versus single kidney transplants from marginal donors

\begin{tabular}{|c|c|c|c|c|c|}
\hline & & & $\begin{array}{l}\text { DGF } \\
\mathrm{n}(\%)\end{array}$ & $\begin{array}{l}\text { Graft survival } \\
\mathrm{n}(\%)\end{array}$ & $\begin{array}{l}\text { Serum creatinine } \\
\mathrm{mg} / \mathrm{dl}\end{array}$ \\
\hline $\begin{array}{l}\text { Alfrey et al. } \\
\text { [Transplantation, 1997] }\end{array}$ & $\begin{array}{l}\text { Dual }^{1} \\
\text { Single }^{1}\end{array}$ & $\begin{array}{l}(n=15) \\
(n=37)\end{array}$ & $\begin{array}{c}1(9) \\
17(45)\end{array}$ & $\begin{array}{l}13(87) \\
30(81) \\
\text { at } 1 \text { year post-Tx }\end{array}$ & $\begin{array}{l}2.0 \\
2.1 \\
\text { at } 6 \text { months post-Tx }\end{array}$ \\
\hline $\begin{array}{l}\text { Lu et al. } \\
\text { [Arch Surg, 1999] }\end{array}$ & $\begin{array}{l}\text { Dual } \\
\text { Single }\end{array}$ & $\begin{array}{l}(n=50) \\
(n=73)\end{array}$ & $\begin{array}{l}13(26) \\
28(39)\end{array}$ & $\begin{array}{l}42(85) \\
61(84) \\
\text { at } 2 \text { years post-Tx }\end{array}$ & $\begin{array}{l}1.6 \\
1.7 \\
\text { at } 2 \text { years post-Tx }\end{array}$ \\
\hline $\begin{array}{l}\text { Jerius et al. } \\
\text { [J Urol, 2000] }\end{array}$ & $\begin{array}{l}\text { Dual } \\
\text { Single }\end{array}$ & $\begin{array}{l}(\mathrm{n}=28) \\
(\mathrm{n}=21)\end{array}$ & $\begin{array}{l}6(21) \\
5(23)\end{array}$ & $\begin{array}{l}27(96) \\
15(73)^{5} \\
\text { at } 2 \text { years post-Tx }\end{array}$ & - \\
\hline $\begin{array}{l}\text { Dietl et al. } \\
\text { [Transplantation, 2000] }\end{array}$ & $\begin{array}{l}\text { Dual } \\
\text { Single }\end{array}$ & $\begin{array}{l}(n=26) \\
(n=10)\end{array}$ & $\begin{array}{l}8(31) \\
3(30)\end{array}$ & $\begin{array}{l}24(94) \\
9(94] \\
\text { at } 1 \text { year post-Tx }\end{array}$ & $\begin{array}{l}1.6 \\
2.3^{2} \\
\text { at } 1 \text { year post-Tx }\end{array}$ \\
\hline $\begin{array}{l}\text { Andres et al. } \\
\text { [Transplantation, 2000] }\end{array}$ & $\begin{array}{l}\text { Dual } \\
\text { Single }^{6}\end{array}$ & $\begin{array}{l}(n=21) \\
(n=40)\end{array}$ & $\begin{array}{r}4(19) \\
21(52)\end{array}$ & $\begin{array}{l}20(95) \\
36(90) \\
\text { at } 1 \text { year post-Tx }\end{array}$ & $\begin{array}{l}1.6 \\
1.9 \\
\text { at } 1 \text { year post-Tx }\end{array}$ \\
\hline $\begin{array}{l}\text { Alfrey et al. } \\
{[\text { Transplant Proc, 2001] }}\end{array}$ & $\begin{array}{l}\text { Dual } \\
\text { Single }\end{array}$ & $\begin{array}{l}(\mathrm{n}=238) \\
(\mathrm{n}=4,726)\end{array}$ & $\begin{array}{r}76(32) \\
1,654(35)\end{array}$ & $\begin{array}{l}178(75) \\
3,072(65) \\
\text { at } 3 \text { years post-Tx }\end{array}$ & $\begin{array}{l}1.7 \\
2.2 \\
\text { at } 3 \text { years post-Tx }\end{array}$ \\
\hline $\begin{array}{l}\text { Bunnapradist et al. } \\
\text { [J Am Soc Nephrol, 2003] }\end{array}$ & $\begin{array}{l}\text { Dual } \\
\text { Single }^{3}\end{array}$ & $\begin{array}{l}(\mathrm{n}=287) \\
(\mathrm{n}=2,350)\end{array}$ & - & $\begin{array}{l}184(64) \\
1,622(69) \\
\text { at } 3 \text { years post-Tx }\end{array}$ & $\begin{array}{l}- \\
-\end{array}$ \\
\hline $\begin{array}{l}\text { Weighted } \\
\text { average }\end{array}$ & $\begin{array}{l}\text { Dual } \\
\text { Single }\end{array}$ & $\begin{array}{l}(\mathrm{n}=665) \\
(\mathrm{n}=7,257)\end{array}$ & $\begin{array}{r}108(16.3)^{4} \\
1,725(23.7)\end{array}$ & $\begin{array}{r}489(73.5) \\
4,845(66.7)\end{array}$ & $\begin{array}{l}1.7^{4} \\
2.0\end{array}$ \\
\hline $\begin{array}{ll}1 & \text { Donor admission creati } \\
2 & \mathrm{p}<0.05 \text { vs. dual. } \\
3 & \text { Donor over 55 years. } \\
4 & \mathrm{p}<0.05 \text { vs. single. } \\
5 & \mathrm{p}<0.02 . \\
6 & \text { Single kidney from } 60-7 \\
7 & \text { From aged donor }(\geq 54\end{array}$ & $\begin{array}{l}\text { year-old } \\
\text { ars). }\end{array}$ & $\begin{array}{l}<90 \mathrm{ml} / \mathrm{min} \\
\text { nors. }\end{array}$ & & & \\
\hline
\end{tabular}

Primary nonfunction in $16 \%$ of single transplants was the major contributor to the difference in survival between the two groups. Similarly, other investigators studied 26 double renal allograft recipients and 10 patients who received single transplants from old donors (age $>65$ years) [114]. The 1-year patient and transplant survival rates were comparable; however, after 1 year mean serum creatinine values were significantly lower in the two kidney transplant recipients. This points to a better functional reserve of dual transplant patients due to an enhanced nephron supply. Excellent outcome using aged dual kidney has also been documented in a more recent analysis of the UNOS database [113]. Although donor and recipient characteristics in recipients of dual kidney transplants $(n=238)$ were similar to recipients of aged $(\geq 54$ years of age) single kidney $(n=4,746)$, graft survival at 3 years was better in the former group ( 75 vs. $65 \%$ ) as well as graft function measured as serum creatinine concentration.

Despite convincing data favoring the use of dual marginal kidneys for transplantation, there are currently no established guidelines to determine which kidney will do well as single marginal graft and in which case dual transplant should be performed. Suggested criteria include glomerulosclerosis degree ranging from 15 to $50 \%$ and creatinine clearance rates from 50 to $90 \mathrm{ml} / \mathrm{min}$ as exclusion criteria for single graft. Simultaneous dual kidney trans- 


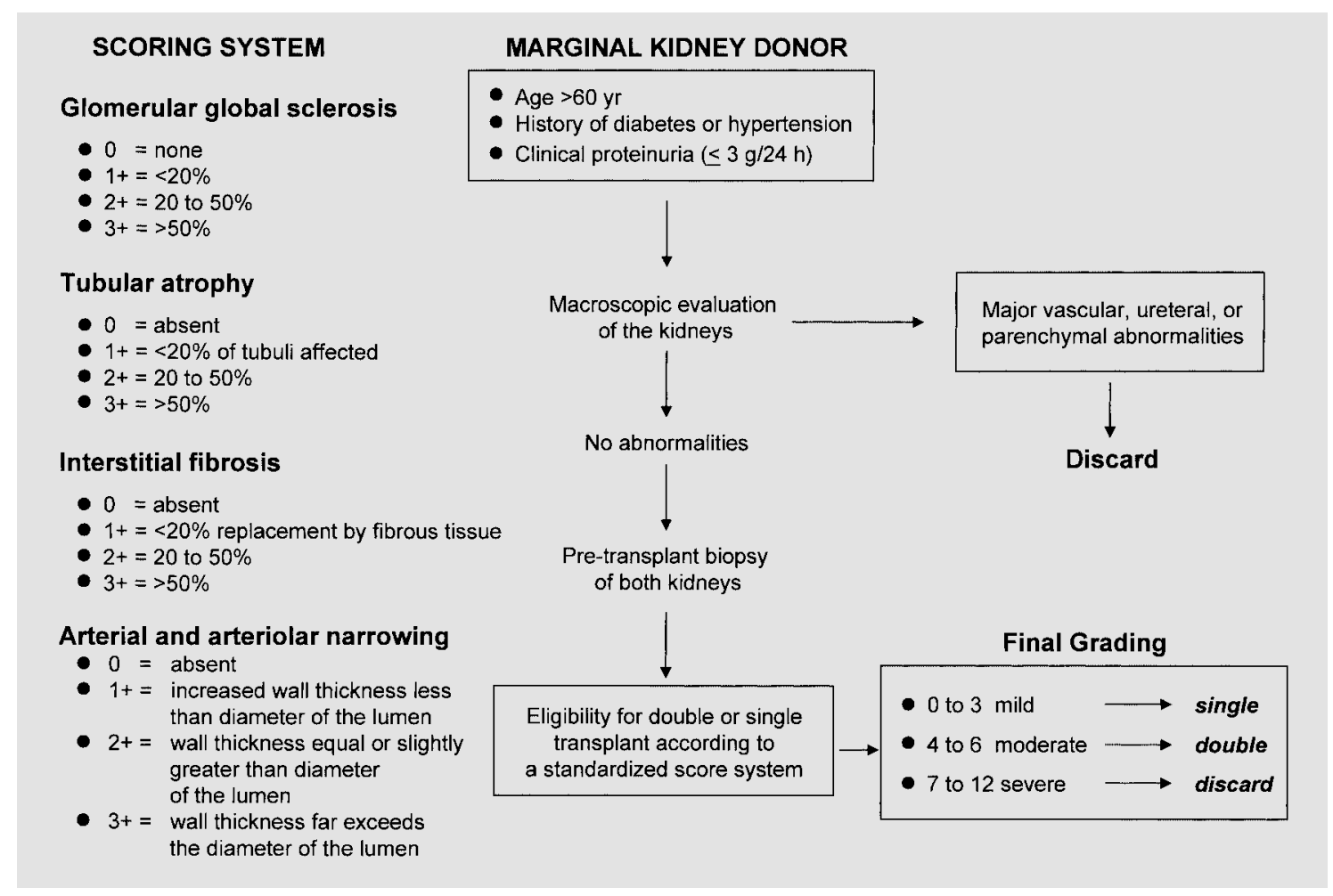

Fig. 1. Proposed algorithm to guide acceptance of a single suboptimal or dual marginal kidneys for transplantation, or to discard them. Donors potentially eligible for suboptimal double or single transplant are identified because of one or more of the following: age $>60$ years, history of diabetes or hypertension, clinical proteinuria. Kidneys are considered eligible only if at macroscopic evaluation major vascular abnormalities that could substantially increase the risk of surgical complications are excluded. A biopsy taken from both kidneys serves to precisely quantify the severity of the tissue damage according to a score system. To limit imprecision in score estimation related to too limited material, only biopsy specimens with at least 25 glomeruli per kidney are considered representative. Kidneys with evidence of acute tubular necrosis are not considered for double transplant. Glo- merular global sclerosis is based on three sections (the first, middle, and last sections, if available) and the number of globally sclerosed glomeruli expressed as a percentage. For the vascular lesions, if the changes are focal the most severe lesion present gives the final grade. The final grade can range from 0 to a total of 12 . Biopsies are graded as mild if they have $0-3$ points in total provided they are less than 3 in any one category. Biopsies are graded as moderate if they have 4 to 6 points in total provided they do not have 3 points in more than one category. Only paired kidneys with a biopsy score of 4-6 are selected for the double transplant. Kidneys with a biopsy score of 3 or less are considered adequate for a single transplant. Those with a score of 7 or more are discarded. plants have been performed when the donor age was 75 years or older, or when the donors between 60 and 74 years old had a glomerulosclerosis rate of $>15 \%$ [103]. Graft survival at 12 months post-transplant (95\%) was comparable to that in recipients of single kidney from donor aged 60-74 years with less than $15 \%$ of glomerulosclerosis on pre-graft biopsy (graft survival: 90\%). From this study, it was suggested that kidneys from extremely elderly donors ( $>75$ years) or those whose glomerulosclerosis $>15 \%$ should be used for simultaneous double kidney transplantation program. Kidneys from donors 60-74 years old, in which the glomerulosclerosis is $<15 \%$, may be transplanted as a single organ. In a recently published study, a scoring system including age $\geq 65$ years, degree of glomerulosclerosis (from 0 to $>30 \%$ ), donor serum creatinine $>1.8 \mathrm{mg} / \mathrm{dl}$, and weight of both kidneys $(<$ or $>300 \mathrm{~g})$ has been reported to make a decision of single or double kidney transplantation [114]. A sum of 1 point or less from all four categories resulted in a regular single kidney transplantation, a sum of 2 points in dual kidney transplantation, and a sum of more than 2 points in refusal of the organ. A comparative analysis of the Dual Kidney Registry and the UNOS Scientific Registry found that dual versus single grafts from marginal donors had a remarkably higher 3-year survival (80.1 vs. 63.9\%) [105]. From this retrospective analysis, a policy of using donors 
$\geq 60$ years of age with creatinine clearance $<90 \mathrm{ml} / \mathrm{min}$ and history of hypertension as a dual transplant was recommended.

Although univocal guidelines to accept a single suboptimal or dual marginal kidneys for transplantation, or to discard both are not available, we are proposing an algorithm (fig. 1) that is supported by the results of a prospective, case-control study of using dual kidney transplantation in adults with expanded donor criteria, in which marginal double versus single transplants were selected on the basis of a predefined score of histologic damage [99]. This includes the overall evaluation of glomerular global sclerosis, tubular atrophy, interstitial fibrosis, and arterial or arteriolar narrowing. The rationale for basing the final eligibility for dual or single transplant from marginal donors according to standardized histologic score system rests on the evidence from several studies that more severe histologic findings at baseline are associated with impaired allograft function at a follow-up period of $1-3$ years [ $42-$ $44,115-117]$. The finding that a 5-year graft survival was $80 \%$ in recipients of kidney donors with $0 \%$ glomerulosclerosis in protocol biopsies taken at engraftment, but was only $35 \%$ in those whose kidney donor biopsy had $>20 \%$ of sclerotic glomeruli [22], further supports the value of histology criteria for appropriate allocation of kidneys from a marginal donor. Examination of kidney tissue provides an objective tool on the state of kidneys that cannot be deduced from clinical records and renal functional studies. Serum creatinine is an insensitive measurement of renal function, especially in those with less than $50 \%$ reduction in glomerular filtration rate, and in older donors [58]. On the other hand, the donor serum creatinine may be markedly elevated in the terminal period because of pre-renal failure or acute tubular necrosis, neither of which is an absolute contraindication to kidney transplantation. Thus, pretransplant donor biopsy is the only reliable tool, not only to evaluate the overall eligibility of the donor kidney, but also to differentiate acute and potentially reversible changes from structural changes associated with irreversibly reduced renal graft reserve.

\section{Conclusions}

The most widespread and successful efforts to enhance the supply of organs available for transplantation have involved expansion of the donor pool to include marginal donors. There are now considerable data and experience to support the policy that no marginal or suboptimal grafts should be discarded due to donor age, diabetes, hypertension, or presence of multiple arteries, providing pre-transplant kidney biopsy is acceptable. Attempts to expand the donor pool with marginal kidneys highlight the need of titrating nephron mass supply to recipient metabolic demand as a possible effective way to prolong long-term organ survival, still the most challenging task of transplant medicine. Efforts to enhance long-term survival is certainly a better strategy than increasing transplant activity, in that it would limit the cost of readmission to dialysis and the need of second transplants. This implies that general accepted definition scoring the degree and correlation of risk factors needs to be established to decide that marginal organs should be accepted or refused. Various opportunities for the improvement of organ quality including donor treatment, modifications of organ perfusions, and age-adapted immunosuppression regimens are now available.

Over the short-term, the policy of using marginal kidney donors have resulted in successful increased utilization of organs that normally would not be considered for transplantation, particularly kidneys from older donors. It is estimated that by using such suboptimal donors the current organ supply can be increased by another $25-30 \%$, thus making successful transplantation therapy available to a larger number of patients currently on the rapidly expanding national transplant recipient waiting list all over the world. Specifically, in some centers the impact of the dual marginal kidney policy on the cadaveric renal donor pool has resulted in a $44 \%$ increase in kidney utilization and a $22 \%$ increase in patients transplanted with kidneys from donors over age 60 [118].

Long-term follow-up is now necessary to substantiate satisfactory graft function and survival results so far achieved in the short-term with expanded criteria donor kidneys in single or dual programs. 


\section{References}

1 Matesanz R: International figures on organ donation and transplantation - 2000. Newslett Transplant 2001;6:1-41.

2 Cecka JM: The UNOS Renal Transplant Registry; in Cecka JM, Terasaki PI (eds): Clinical Transplants 2001. Los Angeles, UCLA Immunogenetics Center, 2002, pp 1-18.

3 Renal Data System: USRDS 1998 annual data report. Bethesda, MD: National Institute of Diabetes and Digestive Kidney Diseases. NIH Publ 98-3176 1998, April, p 39.

4 UNOS Critical Data: Waiting list. http://www unos org 2002. Last update Dec 2001.

5 Plotkin JS, Ridge L, Kuo PC, et al: Extending the boundaries of acceptable organ donors: A means of expanding the donor pool for liver transplantation. Transplant Proc 1997;29: 3288.

6 Ratner LE, Kraus E, Magnuson T, et al: Transplantation of kidneys from expanded criteria donors. Surgery 1996;119:372-377.

7 Kron IL, Tribble CG, Kern JA, et al: Successful transplantation of marginally acceptable thoracic organs. Ann Surg 1993;217:518-522.

8 Copeland JG: Cardiac transplantation after 60 years of age. Ann Thorac Surg 1988;45:115.

9 Alexander JW, Zola JC: Expanding the donor pool: Use of marginal donors for solid organ transplantation. Clin Transplant 1996;10:119.

10 Madden RL, Munda R, Hariharan S, et al: Outcome of cadaver kidneys using nonideal donors. Transplant Proc 1993;25:1568.

11 Troppmann C, Almond PS, Escobar FS, et al: Donor age and cause of death affect cadaver renal allograft outcome. Transplant Proc 1991; 23:1365-1366.

12 Smith KGC, Martyn BN, Walker RG, et al: The potential for elderly donors to increase renal transplantation rates in Australia. Med J Aust 1993; 158:588.

13 Rosenthal JT, Miserantino DP, Mendez R, et al: Extending the criteria for cadaver kidney donors. Transplant Proc 1990;22:338-339.

14 Takiff H: Donor Factors; in Terasaki P (ed) Clinical Transplants 1989. Los Angeles, UCLA Tissue Typing Laboratory, 1990, p 417.

15 Starzl TE: Foreword; in: Toledo-Pereyra LH (ed): Complications of Organ Transplantation. Marcel Dekker, New York, 1987, vol VII.

16 Sweeney MS, Lammermeier DE, Frazier $\mathrm{OH}$ et al: Extension of donor criteria in cardiac transplantation: surgical risk versus supplyside economics. Ann Thorac Surg 1990;50:710

17 Pruim J, Klompmaker IJ, Haagsma EB, et al: Selection criteria for liver donation: A review. Transplant Int 1993;6:226-235.

18 Post J, Miller CM, Schwartz ME, et al: Is it safe to liberalize donor criteria to include those over age 60 and those weighing over $90 \mathrm{~kg}$ ? Transplant Proc 1993;25:1570.

19 Kennedy AP, West JC, Kelley SE, et al: Utilization of trauma-related deaths for organ and tissue harvesting. J Trauma 1992;33:516-519.
20 Shumway SJ, Hertz MI, Petty MG, et al: Liberalization of donor criteria in lung and heartlung transplantation. Ann Thorac Surg 1994; 57:92-95.

21 Pessione F, Cohen S, Durand D, et al: Multivariate analysis of donor risk factors for graft survival in kidney transplantation. Transplantation 2003;75:361-367.

22 Escofet X, Osman H, Griffiths DFR, et al: The presence of glomerulosclerosis at time zero has a significant impact on function after cadaveric renal transplantation. Transplantation 2003; 75:344-346

23 Cofan F, Oppenheimer F, Campistol JM, et al: Advanced age donors in the evolution of renal transplantation. Transplant Proc 1995;28: 2248-2249.

24 Basar H, Soran A, Shapiro R, et al: Renal transplantation in recipients over the age of 60 : The impact of donor age. Transplantation 1999;67: 1191-1193.

25 Matas AJ, Gillingham K, Payne WD, et al: Should I accept this kidney? Clin Transplant 2000;14:90-95.

26 Moreso F, Seron D, Gil-Vernet S, et al: Donor age and delayed graft function as predictors of renal allograft survival in rejection-free patients. Nephrol Dial Transplant 1999;14:930935.

27 Lee CM, Carter JT, Randall HB, et al: The effect of age and prolonged cold ischemia times on the national allocation of cadaveric renal allografts. J Surg Res 2000;91:83-88.

28 De Fijter JW, Mallat MJK, Doxiadis IIN, et al: Increased immunogenecity and cause of graft loss of old donor kidneys. J Am Soc Nephrol 2001; 12:1538-1546.

29 Terasaki PI, Gjertson DW, Cecka JM, et al: Fit and match hypothesis for kidney transplantation. Transplantation 1997;62:441-445.

30 Lloveras J, Arias M, Puig JM, et al: Long-term follow-up of recipients of cadaver kidney allografts from elderly donors. Transplant Proc 1993;25:3175-3176.

31 Kumar MS, Stephan R, Chui J, et al: Donor age and graft outcome in cadaver renal transplantation. Transplant Proc 1993;25:3097-3098.

32 Cantarovich D, Giral-Classe M, Le Sant JN, et al: Renal transplantation from cadaver donors over 60 years old. Clin Transplant 1994;8:237242.

33 Sautner T, Gotzinger P, Wasmer P, et al: Impact of donor age on graft function in 1,180 consecutive kidney recipients. Transplant Proc 1991;23:2598-2601.

34 Lloveras J, Arias M, Andres A, et al: Five-year follow-up of 250 recipients of cadaveric kidney allografts from donors older than 55 years of age. Transplant Proc 1995;27:981-983.

35 Prommool S, Jhangri GS, Cockfield SM, et al: Time dependency of factors affecting renal allograft survival. J Am Soc Nephrol 2000;11: 565-573.

36 Cecka JM, Terasaki PI: Optimal use for older donor kidneys: Older recipients. Transplant Proc 1995;27:801-802.
37 Schlieper G, Ivens K, Voiculescu A, et al: Eurotransplant senior program 'old for old': Results from 10 patients. Clin Transplant 2001;15: 100-105.

38 Kasiske BL, Snyder J: Matching older kidneys with older patients does not improve allograft survival. J Am Soc Nephrol 2002;13:10671072.

39 Vianello A, Mastrosimone S, Calconi G, et al: Influence of donor age on cadaveric kidney graft function and survival: Univariate and multivariate analyses. Nephron 1993;65:541548.

40 Kaplan C, Pasternack B, Shah H, et al: Agerelated incidence of sclerotic glomeruli in human kidneys. Am J Pathol 1975;80:227-234.

41 Fliser D, Franek E, Ritz E: Renal function in the elderly - is the dogma of an inexorable decline of renal function correct? Nephrol Dial Transplant 1997;12:1553-1555.

42 Randhawa PS, Minervini MI, Lombardero M, et al: Biopsy of marginal donor kidneys: Correlation of histologic findings with graft dysfunction. Transplantation 2000;69:1352-1357.

43 Pokorna E, Vitko S, Chadimova M, et al: Proportion of glomerulosclerosis in procurement wedge renal biopsy cannot alone discriminate for acceptance of marginal donors. Transplantation 2000;69:36-43.

44 Gaber LW, Moore LW, Alloway RR, et al: Glomerulosclerosis as a determinant of post-transplant function of older donor renal allografts. Transplantation 1995;60:334-339.

45 Leunissen KM, Bosman FT, Nieman FH, et al: Amplification of the nephrotoxic effect of cyclosporine by preexistent chronic histological lesions in the kidney. Transplantation 1989;48: 590-593.

46 Nghiem DD, Cottington EM, Hsia S: Transplantation of extreme age donor kidneys. Transplant Proc 1993;25:1567.

47 Abouna GM, Adnani MS, Kremer GD, et al: Reversal of diabetic nephropathy in human cadaveric kidneys after transplantation into non-diabetic recipients. Lancet 1983;12741276.

48 Spees EK, Orlowski JP, Fitting KM, et al: Successful use of cadaver kidneys from diabetic donors for transplantation. Transplant Proc 1990;22:378-379.

49 Orlowski JP, Spees EK, Aberle CL, et al: Successful use of kidneys from diabetic cadaver kidney donors: 67- and 44-month graft survival. Transplantation 1994;57:1133-1134.

50 Gomez E, Aguado S, Tejada F, et al: Successful transplant of kidneys with diffuse diabetic glomerulosclerosis. Transplantation 1995;59: 156-157.

51 Talbot D, Reddy KS, Pleass H, et al: Diabetic matching in renal transplantation. Transplantation 1995;59:927-928.

52 Ojo AO, Hanson JA, Meier-Kriesche HU, et al Survival in recipients of marginal cadaveric donor kidneys compared with other recipients and wait-listed transplant candidates. J Am Soc Nephrol 2001;12:589-597. 
53 Frei U, Schindler R, Wieters D, et al: Pre-transplant hypertension: A major risk factor for chronic progressive renal allograft dysfunction? Nephrol Dial Transplant 1995;10:1206-1211.

54 Carter JT, Lee CM, Weinstein RJ, et al: Evaluation of the older cadaveric kidney donor: The impact of donor hypertension and creatinine clearance on graft performance and survival. Transplantation 2000;70:765-771.

55 Opelz G, Wujciak T, Ritz E: Association of chronic kidney graft failure with recipient blood pressure. Kidney Int 1998;53:217-222.

56 Verran DJ, deLeon C, Chui AK, et al: Factors in older cadaveric organ donors impacting on renal allograft outcome. Clin Transplantation 2001;15:1-5.

57 Roodnat JI, Mulder PGH, van Riemsdijk IC, et al: Ischemia times and donor serum creatinine in relation to renal graft failure. Transplantation 2003;75:799-804.

58 Swedko PJ, Clark HD, Paramsothy K, et al: Serum creatinine is an inadequate screening test for renal failure in elderly patients. Arch Intern Med 2003;163:356-360.

59 Kumar MSA, Stephan R, Chui J, et al: Comparative study of cadaver donor kidneys preserved in University of Wisconsin solution for less than or longer than 30 hours. Transplant Proc 1993;25:2265-2266.

60 Alexander JW, Bennett LE, Breen TJ: Effect of donor age on outcome of kidney transplantation. Transplantation 1994;57:871

61 Held PJ, Kahan BD, Hunsicker LG, et al: The impact of HLA mismatches on the survival of first cadaveric kidney transplants. N Engl J Med 1994;331:765-770.

62 Heineman E, Daemen JHC, Kootstra G: Nonheart beating donors: Methods and techniques Tranplant Proc 1995;28:2895-2896.

63 Brook NR, Waller JR, Nicholson ML: Nonheart-beating kidney donation: Current practice and future developments. Kidney Int 2003; 63:1516-1529.

64 Cho YW, Terasaki PI, Cecka JM, et al: Transplantation of kidneys from donors whose hearts have stopped beating. $\mathrm{N}$ Engl J Med 1998;338:221-225.

65 Tanabe K, Oshima T, Tokumoto T, et al: Long term renal function in non-heart beating donor kidney transplantation. Transplantation 1998 ; 66:1708-1713.

66 Wijnen RMH, Booster MH, Stubenitsky BM, et al: Outcome of transplantation from nonheart-beating donor kidneys. Lancet 1995;345: 1067-1070.

67 Swanson M, Schweizer RT, Roper L, et al: Kidney transplantation from asystolic cadaveric donors. Transplant Proc 1997;29:3488.

68 Morpurgo E, Rigotti P, Ancona E: Is warm ischaemia the main limiting factor in the use of non-heart-beating donors in renal transplantation? Transplant Proc 1993;25(suppl 1):1509_ 1510 .

69 Casavilla A, Ramirez C, Shapiro R, et al: Experience with liver and kidney allografts from non-heart-beating donors. Transplantation 1995;59:197-203
70 Koffman CG, Bewick M, Chang RWS, et al: Comparative study of the use of systolic and asystolic kidney donors between 1988 and 1991. Transplant Proc 1993;25:1527-1529.

71 Vanrenterghem Y: Cautious approach to use non-heart-beating donors. Lancet 2000;1:528.

72 Benedetti E, Troppmann C, Gillingham K, et al: Short-and long-term outcomes of kidney transplants with multiple renal arteries. Ann Surg 1995;221:406-414.

73 Khauli R: Surgical aspects of renal transplantation: New approaches. Urol Clins N Am 1994; 2:321-341

74 Ganesan KS, Huigol AK, Sundar S, et al: Management of multiple arteries in renal transplantation. Transplant Proc 1994;26:2101-2102.

75 Golconda MS, Whiting JF, Smith R, et al: Long-term outcome of kidney transplantation from expanded criteria donors: A single center experience. Transplant Proc 1997;29:33793381.

76 Berardinelli L, Pasciucco A, Pozzoli E, et al: Kidneys from border-age donors in the cyclosporine era: Long-term function and outcome. Transplant Proc 1999;31:294-295.

77 Mascaretti L, Pappalettera M, Gravame V, et al: Cadaver kidney transplantation using donors with hypertension in the North Italy transplant program. Transplant Proc 1990;22:382.

78 Laupacis A, Keown P, Pus N, et al: A study of the quality of life and cost-utility of renal transplantation. Kidney Int 1996;50:235-242.

79 Jofre R, Lopez-Gomez JM, Moreno F, et al: Changes in quality of life after renal transplantation. Am J Kidney Dis 1998;32:93-100.

80 Whiting JF, Zavala EY, Alexander JW, et al: The cost-effectiveness of transplantation with expanded donor kidneys. Transplant Proc 1999;31:1320-1321.

81 Schnuelle P, Lorenz D, Trede M, et al: Impact of cadaveric transplantation on survival in endstage renal failure: Evidence for reduced mortality risk compared with hemodialysis during long-term follow-up. J Am Soc Nephrol 1998;9: 2135-2141.

82 Wolfe RA, Ashby VB, Milford EL, et al: Comparison of mortality in all patients on dialysis, patients on dialysis awaiting transplantation, and recipients of a first cadaveric transplant. $\mathrm{N}$ Engl J Med 1999;341:1725-1730

83 Schaubel D, Desmeules M, Mao Y, et al: Survival experience among elderly end-stage renal disease patients: A controlled comparison of transplantation and dialysis. Transplantation 1995;60:1389-1394.

84 Port FK, Wolfe RA, Mauger EA, et al: Comparison of survival probabilities for dialysis patients vs. cadaveric renal transplant recipients. JAMA 1993;270:1339-1343.

85 Ojo AO, Wolfe RA, Agodoa LY, et al: Prognosis after primary renal transplant failure and the beneficial effects of repeat transplantation. Multivariate analyses from the United States Renal Data System. Transplantation 1998;66: 1651-1659.

86 Brenner BM, Cohen RA, Milford EL: In renal transplantation, one size may not fit all. J Am Soc Nephrol 1992;3:162-169.
87 Rennke HG: Pathology of glomerular hyperfiltration; in Mitch WE, Brenner BM, Stein JH (eds): The Progressive Nature of Renal Disease: Contemporary Issues in Nephrology. New York, Churchill-Livingstone, 1986.

88 MacKenzie HS, Azuma H, Rennke HG, et al: Renal mass as a determinant of late allograft outcome: Insights from experimental studies in rats. Kidney Int 1995;52:S38-S42.

89 Taal MW, Tilney NL, Brenner BM, et al: Renal mass: An important determinant of late allograft outcome. Transplant Rev 1998; 12:74-84.

90 Johnson LB, Kuo PC, Dafoe DC, et al: The use of bilateral adult renal allografts: A method to optimize function from donor kidneys with suboptimal nephron mass. Transplantation 1996;61:1261-1263

91 Johnson LB, Kuo PC, Dafoe DC, et al: Double adult renal allografts: A technique for expansion of the cadaveric donor pool. Surgery 1996;120:580-584.

92 Alfrey EJ, Lee CM, Scandling JD, et al: When should expanded criteria donor kidneys be used for single versus dual kidney transplants? Transplantation 1997;64:1142-1146.

93 Stratta RJ, Bennett L: Preliminary experience with double kidney transplants from adult cadaveric donors: Analysis of united network for organ sharing data. Transplant Proc 1997; 29:3375-3376.

94 Lu AD, Carter JT, Weinstein RJ, et al: Excellent outcome in recipients of dual kidney transplants. Arch Surg 1999;134:971-976.

95 Hesse UJ, Vermassen F, Lameire N, et al: Expanded criteria donors and dual kidney transplantation. Transplant Int 1998;11:457458.

96 Andrés A, Herrero JC, Praga M, et al: Double kidney transplant (dual) with kidneys from older donors and suboptimal nephronal mass. Transplant Proc 2001;33:1166-1167.

97 Rigotti P, Cadrobbi R, Furian L, et al: Shortterm outcome of dual kidney transplantation at a single center. Transplant Proc 2001;33: 3771-3773.

98 Knight AJ, Ali AA, White SA, et al: Dual renal transplant from a non-heart beating donor. Transplant Int 1999;12:466-467.

99 Remuzzi G, Grinyo J, Ruggenenti P, et al: Early experience with dual kidney transplantation in adults using expanded donor criteria. J Am Soc Nephrol 1999;10:2591-2598.

100 Lee CM, Scandling JD, Pavlakis M, et al: A review of the kidneys that nobody wanted: Determinants of optimal outcome. Transplantation 1998;65:213-219.

101 Dafoe DC, Alfrey EJ: The expanded donor kidney: The Stanford experience with dual grafts. Grafts 1998;1:11-12.

102 Johnson LB, Kuo PC, Schweitzer EJ: Double renal allografts. Transplant Rev 1998;12:59_ 63.

103 Andres A, Morales JM, Herrero JC, et al: Double versus single renal allografts from aged donors. Transplantation 2000;69:20602066 . 
104 Remuzzi G, Ruggenenti P, Locatelli G, et al: Double transplant of marginal kidneys is safe and allows a faster function recovery than single transplant of optimal kidneys. J Am Soc Nephrol 1998;9:694A.

105 Lu AD, Carter JT, Weinstein RJ, et al: Outcome in recipients of dual kidney transplants. Transplantation 2000;69:281-285.

106 Remuzzi G, Ruggenenti P: Renal transplantation: Single or dual for donors aging $>60$ years? Transplantation 2000;69:2000-2004.

107 Alfrey EJ, Lerner SM, Lu AD: The dual kidney transplant registry; in Cecka JM, Terasaki PI (eds): Clinical Transplants 2001. Los Angeles, UCLA Immunogenetics Center, 2002, pp 107-111.

108 The US Scientific Registry of Transplant Recipients: 2000 Annual Report. Department of Health and Human Services and the United Network for Organ Sharing, 2001.
109 Lee RS, Miller E, Marsh CL, et al: Intermediate outcomes of dual renal allografts: The University of Washington experience. J Urol 2003;169:855-858.

110 Bunnapradist S, Gritsch HA, Peng A, et al: Dual kidneys from marginal adult donors as a source for cadaveric renal transplantation in the United States. J Am Soc Nephrol 2003; 14:1031-1036.

111 Sola R, Guirado LL, Diaz JM, et al: Renal transplantation with elderly donors: Double or single renal transplantation? Transplant Proc 2002;34:345-346.

112 Jerius JT, Taylor RJ, Murillo D, et al: Double renal transplants from marginal donors: 2year results. J Urol 2000;163:423-425.

113 Alfrey EJ, Lu AD, Carter JT, et al: The dual kidney transplant registry. Transplant Proc 2001;33:1099-1100.
114 Dietl KH, Wolters H, Marschall B, et al: Cadaveric 'two-in-one' kidney transplantation from marginal donors: Experience of 26 cases after 3 years. Transplantation 2000;70: 790-794.

$115 \mathrm{Lu}$ AD, Desai D, Myers BD, et al: Severe glomerulosclerosis is not associated with poor outcome after kidney transplantation. Am J Surg 2000;180:470-474.

116 Pokorna E, Vitko S, Chadimova M, et al: Adverse effect of donor arteriosclerosis on graft outcome after renal transplantation. Nephrol Dial Transplant 2000;15:705-710.

117 D'Agati VD, Cohen DJ: Preimplantation renal biopsy: Structure does predict function. Transplantation 2003;75:264-266.

118 Johnson LB, Kuo PC, Schweitzer EJ, et al: Double renal allografts successfully increase utilization of kidneys from older donors within a single organ procurement organization. Transplantation 1996;62:1581-1583. 